\title{
How Do Computer Engineering Students Construe Usability and Accessibility? A Comparative Study between Turkey and Kyrgyzstan
}

\author{
Yavuz INAL, Rita ISMAILOVA
}

\begin{abstract}
This survey study evaluated the level of education, awareness and knowledge of prospective software developers in the areas of usability and accessibility by comparing the results obtained from computer engineering students from Kyrgyzstan and Turkey. There were a total of 311 student participants who were attending a computer engineering program in eight universities, four in Kyrgyzstan and four in Turkey. According to the results, these two countries with different education systems had significant differences in terms of the level of the education of the computer engineering students, their knowledge, awareness and attitude concerning usability and accessibility. Although the overall level of knowledge and awareness of the Turkish students was found to be higher than those of the Kyrgyz students, the computer engineering students in the selected Kyrgyz universities either had taken or were planning to take more courses on accessibility and had a higher level of awareness in terms of undertaking thesis and project work in this area. However, the results obtained from the participants from both countries demonstrated the need for the revision of course content to assist future software developers gain not only technical but also acquire soft skills in the topics of usability and accessibility.
\end{abstract}

Keywords: accessibility; computer engineering; education; human-computer interaction; usability

\section{INTRODUCTION}

The effective, efficient and satisfactory use of applications is directly associated with the extent to which the two pillars of human-computer interaction, usability and accessibility, are considered during the development of these applications. However, despite the long-term emphasis on the need to incorporate usability and accessibility into the software development life cycle, in practice such activities are still not part of software development processes [1,2,3], being often overlooked in the presence of other software engineering activities during software design and development [4]. Many applications are designed and developed without utilizing usability methods and therefore are not considered mature in terms of usability [5], which results in complaints from users and reduced satisfaction [6]. In the literature, several studies have emphasized that usability and accessibility activities are not well integrated into software engineering processes $[3,7,8,9]$.

In order to overcome the challenges facing the integration of usability and accessibility into the software development process, it is of crucial importance to educate and train people that are not experts in the field $[3,10]$. However, the inaccurate and inadequate content of humancomputer interaction courses offered to prospective software developers has been suggested as one of the major reasons behind the poorly designed user interfaces in the software world [11]. Furthermore, there is a significant need to develop a computer science and engineering curriculum, which would not be restricted to providing only theoretical knowledge and would include practical real-life implementations [4, 12, 13].

Graduates of computer science and engineering are now expected to have developed different basic skills that fulfil the requirements for knowledge and capabilities in the area of human-computer interaction [14]. The literature emphasizes that usability activities should be conducted not only by the experts in the field but also other members of a project team that are responsible for designing and developing the software [4]. Therefore, it is important to provide all employees engaged in a software project the opportunities of training in usability and accessibility to increase their level of knowledge and awareness of these areas.

There is a need for more research to develop awareness concerning the importance of integrating usability activities into engineering education [13]. Furthermore, an investigation into the level of awareness of software developers regarding accessibility can provide an insight into the efficiency of, and challenges faced in education programs, courses and regulations that aim to encourage accessibility [3]. In this respect, it is important to determine the level of knowledge and awareness of the developers, as significant stakeholders in the software world, pertaining to usability and accessibility activities. Therefore, the aim of this study was to evaluate the level of education, knowledge and awareness of future software developers by comparing the results obtained from the computer engineering students in Kyrgyzstan and Turkey.

\section{RELATED WORK}

Even though human-computer interaction is usually not integrated into the software development life cycle at the desired level $[8,15]$, usability activities are increasingly becoming more important for the software world and in recent years; thus, organizations have increasingly developed an interest in such activities $[1,4,5]$. This change can be mostly attributed to the negative feedback from users [1]. In particular, an increasing number of largescale software companies place a greater emphasis on utilizing usability engineering methods in their development processes [10]. Several studies (e.g., $[16,17])$ have shown that large- and medium-scale software companies now employ experts in usability; however, the small-scale companies lack the financial resources to recruit people specializing in this area.

Software companies that wish to integrate usability activities into their development processes mostly face two challenges; a lack of usability experts in the sector that could guide the company in this process and budget restrictions, particularly experienced by small-scale companies, which results in them not being able to employ 
people that are field experts or to seek consultancy in this area [10]. Another obstacle to the integration of humancomputer interaction processes into software development projects is the lack of knowledge regarding usability activities [15]. Therefore, it is of critical importance to provide usability training for non-expert personnel particularly in small-scale companies to reduce the problems caused by the lack of expert personnel [10].

Since accessibility is extremely valuable in terms of building an inclusive information society, and improving accessibility, there is a need to increase people's awareness [3]. It is crucial to consider and implement accessibility activities in the software development life cycle from the very beginning of a project [3]. However, today, many software products still do not possess features that would make them more accessible [3,18]. Despite the significant market share of the software products developed for disabled people, many software developers fail to recognize the problems related to accessibility [19]. For example, in a study that aimed to determine the awareness of web application developers concerning accessibility [3], web application projects were found to be far from encouraging accessibility activities and the majority of the employees did not undertake such activities. This situation has been attributed to the employees' lack of education and training in accessibility. Research [20] suggested that particularly web developers should not only know the required standards but also be knowledgeable about the ways of creating more user-friendly designs for disabled users.

Research [9] investigated the obstacles encountered by IBM developers when designing accessible web applications and reported that despite the high motivation of developers to create such designs, they often failed due to their lack of the required capabilities and the incompatibility of new standards or assistive technologies. Many developers that actively work in the development processes of software projects have still not developed an awareness of how accessibility activities can be integrated into these processes [3].

One of the greatest obstacles to designing software products that are both usable and accessible is the lack of training that would increase software developers' competence in these areas. Research [15] suggested that a prominent reason for the problems encountered in the integration of human-computer interaction activities into software development projects is the fact that new software developers, in particular, do not have sufficient knowledge and training in usability. According to [3] and [21], the underlying factor for the poor awareness of many software developers concerning accessibility activities is also their lack of training in accessibility.

The majority of studies reported that there are no courses on human-computer interaction in the undergraduate computer science and engineering curricula $[12,14]$ with such courses being only offered in later stages of education such as Master's programs [12, 13]. In addition, it is emphasized that the content of the existing courses does not meet the requirements or expectations of students [11]. Research [11] analysed the content of human-computer interaction education and underlined the importance of including the basic principles and standards required for designing usable interfaces in the course content.

Various authors have commented that software developers graduate from their education programs only with a basic and inadequate level of education in usability and user requirements [12, 22]. Research [23] investigated the areas in which software professionals worked, which topics they considered being important for their work and the topics provided in their current education that needed improvement. The results showed that one of the major differences between the topics taught during their education and those they needed for their work was related to human-computer interaction. In other words, the participants reported that they did not receive any education in human-computer interaction but they felt the need to be knowledgeable in this area in their work life.

The lack of awareness regarding the knowledge required to develop the appropriate software and usable applications for the target users results from the difference between the requirements of the sector and the content of the courses offered to software developers during their education [24]. Research [24] evaluated the education programs for software development processes and the requirements of the sector in this area, and they concluded that education programs should be designed in a way that develops not only the technical but also soft skills, should be able to quickly adapt to technological advances and incorporate project work and examples from real life.

Although most computer science and engineering graduates do not engage in work, which requires them to be experts of usability and accessibility, they still need to be knowledgeable in these areas due to the requirements of the sector. There is a significant need for courses that incorporate theory and practice into the areas of usability and accessibility to help future developers keep pace with the requirements of this era, be aware of the recent developments and graduate with a higher level of competence. In this respect, identifying the level of education, knowledge and awareness of computer engineering students is valuable for determining whether the need and expectations of the sector in relation to human-computer interaction are sufficiently met.

\subsection{Computer Engineering Education in Kyrgyzstan and Turkey}

In Turkey, an undergraduate program in computer engineering was offered for the first time at the end of the 1970s [25]. As of 2015, more than 100 universities have undergraduate computer engineering programs, some presented in English and others in Turkish [26]. In Turkey, in recent years, course content related to human-computer interaction has been incorporated into undergraduate and master's programs. The content of curriculum is of critical importance for raising competent computer engineers that not only effectively use state-of-the-art technologies but also have a say in the technologies of the future [27]. In Turkey, one of the major problems regarding the computer engineering curriculum is considered to be the lack of project-based course implementations allowing students to put their theoretical knowledge into practice [28]. In addition, providing all types of practical applications designed by considering the needs and expectations of the sector are very important for computer engineering 
education [29]. This also highlights the importance of determining whether the related curriculum effectively responds to new needs and requirements.

Kyrgyzstan is characterized by a high general level of education. The engineering education started with the foundation of the Frunze Polytechnic Institute in 1954 [30] and the first department on computing devices was established in 1969 in the same university [30]. According to the National Statistics Committee of the Kyrgyz Republic, in the 2014-2015 academic year, there were 43,783 students at engineering faculties of Kyrgyz universities [31]. The manual review showed that in 20162017 academic year, 15 universities in the Kyrgyz Republic have programs related to computer and software engineering but they are traditionally known as departments of information technologies or computer science. Only in two universities, the name of the department is computer and software engineering, respectively. However, regardless of the name, the syllabuses of all these departments are moderately similar. Programs are presented mostly in Russian. Human computer interaction course is offered by one university only. In other universities, HCI topics are either considered within other courses or not taught. Up to now, no researches were conducted regarding syllabuses of computer engineering departments in the Kyrgyz Republic.

\section{METHOD}

In this survey study, we aimed to analyse how prospective software developers construe usability and accessibility by comparing the level of education, awareness and knowledge of computer engineering students in Kyrgyzstan and Turkey concerning these areas. The survey was conducted in eight universities, four located in Turkey and four in Kyrgyzstan. Data was collected using quantitative questionnaires with two groups of open-ended questions to measure the students' awareness of usability and accessibility.

The results obtained from the questionnaires were comparatively discussed in relation to the different education systems of Kyrgyzstan and Turkey. Turkish universities follow the Bologna process, which is based on a course credit system. The Kyrgyz Republic is not a member of the Bologna process, and only newly founded universities and those founded in cooperation with foreign countries follow the Bologna process. The majority of the universities are still using the education system adopted in the Soviet time, in which students are not allowed to choose courses, but have to follow a strict schedule with a predefined list of classes.

Since the education systems of Kyrgyzstan and Turkey are different, it was assumed that there would be differences between the computer engineering students from these countries in their responses to the following research questions on usability and accessibility:

- RQ1. Is there a difference between the Kyrgyz and

Turkish students in terms of their perception of usability?

- RQ2. Do the students from Kyrgyzstan and Turkey have the same attitude towards the topic of humancomputer interaction?
- RQ3. Is there a difference between the Kyrgyz and Turkish students in terms of their perception of web accessibility?

- RQ4. Do the students from Kyrgyzstan and Turkey have the same attitude towards web accessibility?

- RQ5. Is the level of students' knowledge on web accessibility standards the same in the Kyrgyz Republic and Turkey?

\subsection{Participants}

Students from four universities in Turkey and four universities in the Kyrgyz Republic were asked to voluntarily participate in this research. The questionnaires were distributed both online and in a paper-based form to the students attending the departments of Computer Engineering of the selected universities. The total sample comprised 311 students $(69.1 \%$ male and $30.9 \%$ female) aged 17 and 39 years; $47.9 \%$ from Turkish universities and $52.1 \%$ from Kyrgyz universities.

\subsection{Materials}

The survey consisted of four sections. The first section contained six questions to obtain demographic and personal information about the students such as their gender, age, country and university as well as internship and work experience including the number of years and area. Furthermore, in this section, the students were asked in which fields of computer engineering they would like to continue their carrier. The second section of the questionnaire contained 16 items, 10 on usability awareness and six on accessibility awareness. The following section aimed to determine students' knowledge of usability with five-point Likert-type questions; 1 indicating no knowledge and 5 indicating a high level of knowledge. This section also inquired whom the students considered responsible for usability in a software development process. The final section of the questionnaire concerned students' level of knowledge regarding accessibility guidelines and principles.

\subsection{Procedure}

The questionnaire was developed by the researchers in Turkish and then translated into Russian. The responses of the students were collected both in the written form through the direct questionnaire method and using an online survey tool. Although the survey was quantitative, open-ended questions were also used and the response rate for some of the open-ended questions reached $21.54 \%$ of all participants. These responses were categorized and used in the analysis. SPSS 22.0 was used to analyse the data.

\section{RESULTS \\ 4.1 Demographics}

Of the 311 participants, $47.9 \%$ were from Turkish universities with $70.47 \%$ male and $29.53 \%$ female and $52.1 \%$ were from Kyrgyz universities with $67.90 \%$ male and $32.10 \%$ female. Fifty-four percent of all students reported to have internship or work experience; however, this rate was found to be higher in Turkey at $80.54 \%$ compared to the Kyrgyz Republic (29.01\%) (Tab. 1). The question on the future field of specialization allowed 
multiple responses. The students showed similar preferences in the choice of future career field; however, the Turkish students seemed to be more determined with only $9.4 \%$ not having decided what to specialize in compared to the higher percentage of undecided Kyrgyz students $(15.43 \%)$. Software development was chosen by $71.14 \%$ of the students from Turkey and $63.58 \%$ of the students from Kyrgyzstan. Network and software security attracted the interest of $26.17 \%$ and $21.6 \%$ of the Turkish and Kyrgyz students, respectively. Business analysis was chosen as a career field by $19.46 \%$ and $17.9 \%$ of the Turkish and Kyrgyz students, respectively and $18.12 \%$ and $11.73 \%$ of the students from Turkey and the Kyrgyz Republic, respectively, wished to become an academician.

\subsection{Usability Awareness of Computer Engineering Students \\ 4.2.1 Attitude towards Usability}

According to [32], usability can be defined by five quality components explained below:

- Learnability: How easy is it for users to accomplish basic tasks the first time they encounter the design?

- Efficiency: Once users have learned the design, how quickly can they perform tasks?

- Memorability: When users return to the design after a period of not using it, how easily can they re-establish proficiency?
- Errors: How many errors do users make, how severe are these errors, and how easily can they recover from the errors?

- Satisfaction: How pleasant is it to use the design?

In this study, the students were given four different definitions of usability and asked to choose the one that best explained the concept through an evaluation based on Nielsen's two quality components, efficiency and user satisfaction as well as two user experience components namely ease of use and reflecting the combined experience by software. The independent t-test was performed on the students' responses to determine whether there was a difference between the Turkish and Kyrgyz students in terms of their perception of software usability (Hypothesis 1). The results of the t-test showed a statistically significant difference between the Turkish and Kyrgyz students in their understanding of the term "usability" based on three components (Tab. 2). The Turkish students have higher priority to all four components of usability while the Kyrgyz students paid more attention only to effectiveness, with the mean difference for the first question being -0.693 . Taking into account that the scale used in this question was from 0 to 5 , the difference was found to be statistically significant. However, the attitude towards one definition of usability ("the software product must meet the requirements of the client") was the same among all the students.

Table 1 Demographic profile of the respondents

\begin{tabular}{|c|c|c|c|}
\hline \multirow{2}{*}{ Category } & \multirow{2}{*}{ Sub-categories } & \multicolumn{2}{|c|}{ Percentages $(\%)$} \\
\hline & & Turkey & Kyrgyzstan \\
\hline \multirow{2}{*}{ Gender } & Male & 70.47 & 67.90 \\
\hline & Female & 29.53 & 32.10 \\
\hline \multirow{2}{*}{$\begin{array}{l}\text { Internship or } \\
\text { work experience }\end{array}$} & Yes & 80.54 & 29.01 \\
\hline & No & 19.46 & 70.99 \\
\hline \multirow{5}{*}{ Career options } & Software development & 71.14 & 63.58 \\
\hline & Business analysis & 19.46 & 17.90 \\
\hline & Network and software security & 26.17 & 21.60 \\
\hline & Academician & 18.12 & 11.73 \\
\hline & Do not know & 9.40 & 15.43 \\
\hline
\end{tabular}

Table 2 Results of the independents t-test on students' perception of usability by country

\begin{tabular}{|l|c|c|c|}
\hline & $t$ & $d f$ & Sig. (2-tailed) \\
\hline $\begin{array}{l}\text { [Usability] is the extent to which a product can be used by specified } \\
\text { users to achieve specified goals with effectiveness, efficiency, and } \\
\text { satisfaction in a specified context of use (ISO 9241-210 [33]). }\end{array}$ & -6.859 & 261.453 & .000 \\
\hline $\begin{array}{l}\text { [Usability] describes the match between a computer system and the } \\
\text { structure and practices of an organization, such that the system can be } \\
\text { effectively integrated into the work practices of the organization's } \\
\text { members ([34] p. 1024). }\end{array}$ & -.997 & 294.551 & -.693 \\
\hline $\begin{array}{l}\text { [User experience] is the perceived attractiveness, ease of use, utility, and } \\
\text { degree of usage of the product ([35] p. 476). }\end{array}$ & -5.393 & 297.993 & .320 \\
\hline $\begin{array}{l}\text { [User experience] is the combined experience of the composition of the } \\
\text { elements of experience, its sensual qualities, related emotions, and the } \\
\text { pervading space and time ([36] p. 42-43). }\end{array}$ & -4.245 & 309 & .000 \\
\hline
\end{tabular}

\subsubsection{Usability Education}

The computer engineering students were asked whether they had received any formal education regarding usability, their future plans for taking courses, experience with undertaking theses and project work in usability and how they followed the recent developments in this area. The questions allowed multiple responses. The results showed that the percent of students, who had not taken any course or training related to usability, was $66 \%$ and $56.4 \%$ in the Kyrgyz Republic and Turkey, respectively.
The percent of students, who had attended a class on usability, was $25.3 \%$ and $39.6 \%$ in the Kyrgyz Republic and Turkey, respectively. In addition, the Kyrgyz students showed more intention to study usability, with $14.8 \%$ planning to participate in a usability course and $8 \%$ choosing a thesis/final project topic related to usability while these percentages were $4 \%$ and $0.7 \%$, respectively among the Turkish students (Tab. 3).

The results were similar for the question on how the respondents followed the recent developments in the field of usability. Most students (31.5\% of Kyrgyz and 48.6 of 
Turkish students) did not follow the news or developments in this field. However, the results revealed that among those who were interested in usability, the Kyrgyz students preferred blogs pages $(37.0 \%)$, books and articles $(30.2 \%)$ while the Turkish students mostly read blog pages $(35.6 \%)$ and technology magazines (23.3\%). In addition, the Kyrgyz students relied on university courses more than the Turkish students.

Table 2 Cross tabulation of students' usability education by country

\begin{tabular}{|l|c|c|c|}
\hline \multirow{2}{*}{} & \multicolumn{2}{|c|}{ Country } & \multirow{2}{*}{ Total } \\
\cline { 2 - 3 } & $\begin{array}{c}\text { Kyrgyz } \\
\text { Republic }\end{array}$ & Turkey & \\
\hline Undergraduate course(s) & $25.3 \%$ & $39.6 \%$ & $32.2 \%$ \\
\hline $\begin{array}{l}\text { Planning to take undergraduate } \\
\text { course(s) }\end{array}$ & $14.8 \%$ & $4.0 \%$ & $9.6 \%$ \\
\hline $\begin{array}{l}\text { Thesis / final project topic is } \\
\text { related to usability }\end{array}$ & $8.0 \%$ & $0.7 \%$ & $4.5 \%$ \\
\hline $\begin{array}{l}\text { Not taken any course / training } \\
\text { related to usability }\end{array}$ & $66.0 \%$ & $56.4 \%$ & $61.4 \%$ \\
\hline
\end{tabular}

The computer engineering students were also asked who they thought should be responsible for usability in a software project. The participants were allowed to choose more than one response. A large percent of students from the Turkish universities chose business analysts (42.3\%), test engineers $(42.3 \%)$ and project managers $(40.9 \%)$ while the Kyrgyz students considered software development engineers $(50.6 \%)$ and project managers $(40.1 \%)$ to be responsible for ensuring the usability software products.

Finally, a t-test was performed on the usability education of the students from both countries to test Hypothesis 2. The results showed that regarding students' attitude towards usability education, six factors were found to statistically significantly differ in the two countries. The first three were; participation in a course on usability, future plans to participate in courses and the thesis or termproject being related to usability. The remaining differences were all related to how the students followed usability topics (e.g., books/articles, attending courses).

\subsubsection{Factors Defining the Level of Usability Knowledge}

The factors that influenced the level of students' usability knowledge were analysed individually for each country by dividing the dataset into two. Then, an ANOVA test was performed. Fourteen variables were chosen as independent factors, including the presence of work or internship experience, career preferences, having taken usability courses or received education on usability and following the developments in usability.

The results showed that in the Kyrgyz Republic, there was a statistically significant difference $(95 \%$ confidence interval) between the students who had studied usability at university and those who had not. Other two factors that significantly influenced the knowledge level of students were reading blogs and books or articles on usability. However, in the case of Turkish students, all the factors but the presence of work or internship experience appeared to be statistically significant in the evaluation of usability knowledge.

\subsection{Accessibility Awareness of Computer Engineering Students \\ 4.3.1 Attitude towards Accessibility}

The computer engineering students were asked which definitions best explained accessibility to determine whether there was a statistical difference between the participants from the two countries. To this end, the participants were asked to arrange the accessibility definitions in order of importance with the highest importance being given 5 points and the lowest 1 point. Based on the students' evaluation of these definitions, an independent t-test was carried out to compare the Kyrgyz and Turkish students in terms of their knowledge and perception of web accessibility (Hypothesis 3).

The results revealed that the Turkish and Kyrgyz students had a similar level of knowledge and perception concerning web accessibility definitions, except for definition 5, which was "The usability of a product, service, environment or facility by people with the widest range of capabilities". The difference between the participants from the two countries in response to this question was statistically significant at the $95 \%$ confidence interval with $p=0.000$ and a mean difference of -0.823 . The mean values were 3.20 and 4.02 for the Kyrgyz Republic and Turkey, respectively (Tab. 4).

\begin{tabular}{|c|c|c|c|c|}
\hline & $t$ & $d f$ & $\begin{array}{l}\text { Sig. }(2- \\
\text { tailed) }\end{array}$ & Mean Difference \\
\hline $\begin{array}{l}\text { The extent to which a product can be used by specified users to achieve specified goals } \\
\text { with effectiveness, efficiency and satisfaction in a specified context of use (ISO, 9241-210, } \\
\text { Usability [33]). }\end{array}$ & -.468 & 362.028 & .640 & -.052 \\
\hline $\begin{array}{l}\text { Person's perceptions and responses resulting from the use and/or anticipated use of a } \\
\text { product, system or service (ISO 9241-210, User Experience [33]). }\end{array}$ & 1.249 & 458 & .212 & .127 \\
\hline $\begin{array}{l}\text { Web accessibility means that people with disabilities can use the Web. More specifically, } \\
\text { Web accessibility means that people with disabilities can perceive, understand, navigate, } \\
\text { and interact with the Web, and that they can contribute to the Web [37]. }\end{array}$ & .446 & 371.894 & .656 & .053 \\
\hline The quality of being able to be reached or entered [38]. & -.271 & 273.172 & .787 & -.025 \\
\hline $\begin{array}{l}\text { The usability of a product, service, environment or facility by people with the widest range } \\
\text { of capabilities (ISO 9241-171:2008, Accessibility [39]). }\end{array}$ & -7.989 & 458 & .000 & -.823 \\
\hline
\end{tabular}

\subsubsection{Accessibility Education}

As in the case of usability education, the participants were directed questions related to their accessibility education allowing multiple responses to test Hypothesis 4 through an independent t-test. The percent of students, who had not taken any course or training on web accessibility, was found to be significantly higher in Turkey $(96.6 \%)$ compared to the Kyrgyz Republic (66\%). On the other hand, the percent of students, who had participated or were planning to participate in courses related to software accessibility, was higher among the Kyrgyz students at $28.4 \%$ and $15.4 \%$, respectively compared to the Turkish students $(2.7 \%$ and $0.7 \%$, respectively). In addition, $6.8 \%$ 
of the Kyrgyz students undertook thesis or final project work related to software accessibility. As is seen the results concerning accessibility education were very similar to those obtained for usability (Tab. 5).

Table 5 Cross tabulation of students' accessibility education by country

\begin{tabular}{|l|c|c|c|}
\hline \multirow{2}{*}{} & \multicolumn{2}{|c|}{ Country } & \multirow{2}{*}{ Total } \\
\cline { 2 - 3 } & $\begin{array}{c}\text { Kyrgyz } \\
\text { Republic }\end{array}$ & Turkey & \\
\hline Undergraduate course(s) & $28.4 \%$ & $2.7 \%$ & $16.0 \%$ \\
\hline $\begin{array}{l}\text { Planning to take undergraduate } \\
\text { course(s) }\end{array}$ & $15.4 \%$ & $0.7 \%$ & $8.3 \%$ \\
\hline $\begin{array}{l}\text { Thesis / final project topic is related to } \\
\text { accessibility }\end{array}$ & $6.8 \%$ & $0.0 \%$ & $3.4 \%$ \\
\hline $\begin{array}{l}\text { Not taken any course / training related } \\
\text { to accessibility }\end{array}$ & $66.0 \%$ & $96.6 \%$ & $80.6 \%$ \\
\hline
\end{tabular}

Students were asked if they have taken any courses or training related to HCI. The question allowed multiple answers in 5 answer options. Of these five options that were identified, the following four were found to be statistically significant, meaning that accessibility education significantly differed in the two countries: participation in accessibility courses, future plans to participate in courses or undertaking thesis or term-project work related to accessibility.

The questionnaire contained items to measure the level of students' knowledge regarding the use of web applications by disabled people. According to the results, the difference between the knowledge of the Turkish and Kyrgyz students on the development of software for disabled people was not statistically significant at the $95 \%$ confidence interval with $p=0.217$. The mean difference was 0.172 , indicating a slightly higher level of knowledge among the Kyrgyz students.

\subsubsection{Knowledge of Accessibility Standards and Assistive Technologies}

The students were asked to evaluate their knowledge of accessibility standards. The percentage of students, who reported to have no knowledge on accessibility standards, significantly differed between the two countries. As shown in Table 6, according to the students' responses, the level of the Kyrgyz students' knowledge was higher than that of the Turkish students. When the similarity between the Kyrgyz and Turkish students' knowledge of web accessibility standards was analysed (Hypothesis 5), the difference was found to be statistically significant at the $95 \%$ confidence interval. Further analysis was carried out using the independent $t$-test. The $p$ value was equal to 0.000 for all the five standards, implying that this statistical difference was high.

The participants were asked about their familiarity with and knowledge of the assistive technologies used by disabled people. Although $19.1 \%$ of the Kyrgyz students and $13.4 \%$ of the Turkish students stated that they were not familiar with any of the existing assistive technologies, the remaining students had some knowledge of these technologies. Among the Kyrgyz students, 50\% reported to be familiar with an alternative keyboard, $47.5 \%$ with alternative mouse and joystick, $45.7 \%$ with screen magnifier and voice recognition tools, $37.7 \%$ with screen readers and $30.2 \%$ with Braille-based tools.

The familiarity of the Turkish students with various assistive technologies was as follows: voice recognition tools $66.4 \%$, screen magnifier $65.8 \%$, screen reader $52.3 \%$, alternative keyboard $45.6 \%$, and alternative mouse and joystick and Braille-based tools $34.2 \%$. These results show that the students' knowledge of assistive technologies differed considerably, with $\mathrm{p}=0.057$ and a mean difference of -0.419 , indicating that the Turkish students were more familiar with these technologies.

Table 6 Students' knowledge of accessibility standards by country

\begin{tabular}{|c|c|c|c|c|c|c|}
\hline \multirow{2}{*}{ Knowledge level } & \multirow{2}{*}{ Country } & \multicolumn{5}{|c|}{ Percent of students that know the standards (\%) } \\
\hline & & WCAG & ATAG & UAAG & ISO 9241-171: 2008 & ISO 9241-210: 2010 \\
\hline \multirow{2}{*}{0 (no knowledge) } & KR & 34.0 & 36.4 & 37.7 & 38.3 & 39.5 \\
\hline & TR & 73.8 & 78.5 & 82.6 & 76.5 & 76.5 \\
\hline \multirow{2}{*}{1} & KR & 12.3 & 15.4 & 14.2 & 13.6 & 11.1 \\
\hline & TR & 12.1 & 2.7 & 6.0 & 6.0 & 4.7 \\
\hline \multirow{2}{*}{2} & KR & 19.1 & 17.9 & 17.3 & 15.4 & 17.3 \\
\hline & TR & 8.7 & 16.1 & 7.4 & 11.4 & 13.4 \\
\hline \multirow{2}{*}{3} & KR & 18.5 & 18.5 & 14.8 & 17.3 & 16.0 \\
\hline & TR & 4.7 & 1.3 & 2.7 & 4.0 & 4.0 \\
\hline \multirow{2}{*}{4} & KR & 11.1 & 6.8 & 11.1 & 8.6 & 10.5 \\
\hline & TR & 0 & 0.7 & 0.7 & 1.3 & 0.7 \\
\hline \multirow{2}{*}{5 (expert level) } & KR & 4.9 & 4.9 & 4.9 & 6.8 & 5.6 \\
\hline & TR & 0.7 & 0.7 & 0.7 & 0.7 & 0.7 \\
\hline
\end{tabular}

\subsubsection{Factors Defining the Level of Accessibility Knowledge}

To define which factors affected the level of accessibility knowledge, the dataset was again divided into two by country and the ANOVA test was carried out for each set. For this test, the following demographic variables were chosen as the independent factors: gender, age, level of education, presence and area of work or internship experience and future career areas of interest.

The results showed that in the Kyrgyz Republic, the difference between the accessibility knowledge of female and male participants was statistically significant at the $95 \%$ confidence level with $p=0.039$. Another factor that significantly influenced the students' knowledge was their experience in the development of a software project in class $(p=0.001)$. For the Turkish students, the significant factors were defined as level of education $(p=0.098)$, durations of internship ( $p=0.094)$ and experience in the development of a software project at work $(p=0.04)$. 


\section{DISCUSSION}

Computer engineering departments largely meet the developer demand of the software world. Therefore, the knowledgeability and awareness of the students enrolled in these departments can have an influence on the usability and accessibility of the applications they develop. However, as a result of being exposed to a considerable number of applications with poorly designed interfaces in their daily life, these students may fail to recognize bad designs or develop an awareness regarding the strong and weak features of a software product [11]. This often presents an obstacle for a person to consider how usable products should be. Research has shown that developers can only discuss the potential usability-related problems of an application at a superficial level and cannot explain these problems in-depth [40].

It is important that computer engineering students know how to integrate their knowledge about usability and related activities into the software development life cycle. For applications to have better usability features, such activities should not be considered as a one-time effort [1]; rather, they should be actively used within the development life cycle throughout the project, which would also ensure that all these efforts produce satisfactory outcomes.

Therefore, in this study, the level of education, awareness and knowledge of computer engineering students in the usability and accessibility fields were comparatively discussed in relation to the Kyrgyz and Turkish participants. According to the results, in these two countries with different education systems, significant differences were found regarding several variables related to these levels. It was observed that the Kyrgyz and Turkish students had statistically significantly different perceptions of the definition of usability. The Turkish students gave priority to all aspects of usability whereas for the Kyrgyz students, usability was mostly associated with the effectiveness of the software.

Research [6] defined the main challenges involved in a software development process as the computer engineers' limited knowledge concerning human-computer interaction and the almost complete absence of usability tests. Therefore, in the present study, we aimed to analyse the usability work undertaken by computer engineering students and the importance they attached to this field. According to the analysis of the attitudes towards studying the usability topic, there were differences between the Kyrgyz and Turkish students in terms of six factors. The Turkish students seemed to be more interested in participating in courses on usability and undertaking usability work in their term projects or theses. On the other hand, the number of the Kyrgyz students that were planning to participate in usability courses was higher. This can be attributed to the relative novelty of this topic in Kyrgyzstan. In addition, because the list of courses that students must participate in is fixed, the Kyrgyz students may be aware in advance of what courses they have to attend. Furthermore, how the students followed software usability topics was found to be similar in the two countries in all factors but one, which was related to the students' willingness to study usability at university (Kyrgyz students: $19.8 \%$ and Turkish students: $1.4 \%$ ).
Considering that receiving even limited hours of training on usability is sufficient to help software developers to detect and find solutions for many errors related to usability in the applications they develop [41], it is clear that integration of usability into formal education would greatly contribute to the improvement of computer engineering students' knowledge and skills in this area. Therefore, it is important to develop an awareness among these students, provide them with learning opportunities and establish necessary support mechanisms to encourage them to participate in courses in this area.

The attitude toward who should be responsible for usability in a software project also was found to be different in two countries in the present study. In a study investigating the level of usability knowledge and awareness of computer engineering graduates in Turkey [42], the developers were found to consider not themselves but the business analysts to be responsible for usability activities in a project team. Similarly, the computer engineering students that participated in the present study believed that they were the least responsible personnel to undertake usability work in projects and they considered that the business analysts and project managers were the major responsible parties. However, the Kyrgyz students were of the opinion that it was particularly the responsibility of software developers to ensure that usability activities were performed in projects. As it was mentioned in [43] if usability is the concern of everyone in the project team, "shared responsibility tends to become nobody's responsibility". In Turkey, there are wide range of specialists responsible for usability of a software product, however in the Kyrgyz Republic the whole process of a software development is still of the developers' responsibility. This fact was reflected in the result of the t-test analysis in this study as well.

When they first begin to work as software developers, most computer engineering graduates do not have sufficient knowledge and awareness concerning accessibility [3]. However, in the software world, they need to know not only the accessibility standards but also how to make a design more user-friendly for the targeted disabled users [20]. In order to develop accessible applications, software developers should improve their skills and knowledge both in the areas of coding and testing [9]. It should also be noted that in a software project, in addition to taking an active part in development processes, developers are also one of the stakeholders who are responsible for the accessibility of the system that is being developed [3]. This further demonstrates the importance of computer engineering students not isolating themselves from accessibility activities and being equipped with a level of knowledge and awareness required to undertake such work.

Research [3] investigated the knowledgeability of the members of a web development project and found that the majority of the participants had little or no knowledge about the Web Content Accessibility Guidelines (WCAG) guidelines on accessibility. Research [44] reported that although developers believe they have sufficient knowledge of the guidelines and standards on accessibility, in fact, their level of knowledge was not advanced. Similarly, in the present study, the computer engineering students from both Kyrgyzstan and Turkey were found to 
have a low level of knowledge regarding accessibility guidelines and standards.

Similar to the previous studies in the literature (e.g. [3]), we found that a considerable number of participants from both countries did not receive any education or training in accessibility. Research [44] also underlined the need for the majority of developers to receive accessibility education and training. Similarly, in the present study, the need for formal education in accessibility was one of the prominent findings. In particular, compared to the Kyrgyz students, a higher percentage of the Turkish students had not received any formal education on accessibility. Furthermore, the Turkish students were found to be less aware of the importance of this area and were less willing to participate in future training programs on accessibility. On the other hand, although Kyrgyz students have reported to have a formal education on accessibility, review of syllabuses in Kyrgyz universities showed that few HCI related courses are present. The overall results showed that the computer engineering students from both countries needed further education and training in accessibility.

Concerning the participants' knowledge of assistive technologies, the students from Kyrgyzstan and Turkey concentrated on different assistive tools. However, similar to earlier studies (e.g. [3]), in the present study, the students were found to be most familiar with voice recognition software, and screen readers and magnifiers.

\section{CONCLUSION}

The results of the present study showed that the computer engineering students did not have a sufficient level of knowledge, awareness and formal education concerning usability and accessibility. In this respect, revising the curriculum of computer engineering programs to incorporate usability and accessibility is essential to provide the prospective developers with not only technical but also the other skills necessary to meet the demands of the software world. This was demonstrated in the present study, in which the Turkish students were found to attach higher importance to usability than accessibility. This can be attributed to the human-computer interaction courses that have been incorporated into computer engineering programs in recent years. On the same basis, the lack of undergraduate or post-graduate courses on accessibility explains the computer engineering students' lower level of knowledge and awareness concerning this area.

As suggested by research [13], the first priority is to emphasize the negative outcomes of not integrating usability into software development; e.g., the need to redesign the interface due to user dissatisfaction or even develop the whole application again. Such undesirable outcomes can be avoided by providing students with appropriate education on usability and accessibility based on human-computer interaction, helping them gain soft skills and learn how to better empathize with users. This will also contribute to the competence of computer engineering graduates and equip them with characteristics that will satisfy the demands of the sector. In addition, the curriculum should be revised at regular intervals to adapt to the new needs and requirements. As a continuation of this work, we plan to investigate the level of education, awareness and knowledge of computer engineering students from different countries concerning the areas of usability and accessibility to recommend a curriculum model based on the results. In addition, it is planned to investigate the real knowledge of students from different countries with their self-esteem in knowledge of $\mathrm{HCI}$ topics.

\section{REFERENCES}

[1] Aucella, A. F. (1997). Ensuring Success with Usability Engineering. Interactions, May-June, 19-22. https://doi.org/10.1145/255392.255395

[2] Carter, J. (1999). Incorporating Standards and Guidelines in an Approach that Balances Usability Concerns for Developers and End Users. Interacting with Computers, 12, 179-206. https://doi.org/10.1016/S0953-5438(99)00011-9

[3] Freire, A. P., Russo, C. M., \& Fortes R. P. M. (2008). A Survey on the Accessibility Awareness of People Involved in Web Development Projects in Brazil. Proceedings of the International Cross-Disciplinary Conference on Web Accessibility (W4A), Beijing, 87-96. https://doi.org/10.1145/1368044.1368064

[4] Karat, J. \& Dayton, T. (1995). Practical Education for Improving Software Usability. Proceedings of the CHI, Colorado, 162-169. https://doi.org/10.1145/223904.223925

[5] Juristo, N. (2009). Impact of Usability on Software Requirements and Design. International Summer Schools, ISSSE 2006-2008, Salerno, Italy, Revised Tutorial Lectures, Springer-Verlag, Berlin, Heidelberg, 55-77. https://doi.org/10.1007/978-3-540-95888-8_3

[6] Vukelja, L., Müller, L., \& Opwis, K. (2007). Are Engineers Condemned to Design? A Survey on Software Engineering and UI Design in Switzerland. Proceedings of the $11^{\text {th }}$ International Conference on Human-Computer Interaction, Rio de Janeiro, 555-568. https://doi.org/10.1007/978-3-540-74800-7_50

[7] Bias, R. G. \& Mayhew, D. J. (2005). Cost-Justifying Usability: An Update for the Internet Age. Elsevier, Amsterdam. https://doi.org/10.1016/B978-012095811-5/50001-8

[8] Seffah, A., Desmarais, M. C., \& Metzker, E. (2005). HCI, Usability and Software Engineering Integration: Present and Future. In A. Seffah, J. Gulliksen, and M. C. Desmarais (eds.), Human-Centered Software Engineering: Integrating Usability in the Development Process. Springer, Dordrecht, 37-57. https://doi.org/10.1007/1-4020-4113-6_3

[9] Trewin, S., Cragun, B., Swart, C., Brezin, J., \& Richards, J. (2010). Accessibility Challenges and Tool Features: An IBM Web Developer Perspective. Proceedings of the International Cross-Disciplinary Conference on Web Accessibility (W4A), Raleigh, Article No: 32.

[10] Bruun, A. (2010). Training Software Developers in Usability Engineering: A Literature Review. Proceedings of the $6^{\text {th }}$ Nordic Conference on Human-Computer Interaction, Reykjavik, 82-91. https://doi.org/10.1145/1868914.1868928

[11] Edwards, A. D. N., Wright, P., \& Petrie, H. (2006). HCI Education: We are Failing-Why? Proceedings of the HCI Educators Workshop, Limerick, 127-129.

[12] Faulkner, X. \& Culwin, F. (2000). Enter the Usability Engineer: Integrating $\mathrm{HCI}$ and Software Engineering. Proceedings of the ITISCE, Helsinki, 61-64. https://doi.org/10.1145/343048.343076

[13] Holzinger, A., Errath, M., Searle, G., Thurnher, B., \& Slany, W. (2005). From Extreme Programming and Usability Engineering to Extreme Usability in Software Engineering Education (XP+UE->XU). Proceedings of the $29^{\text {th }}$ Annual International Computer Software and Applications Conference, Edinburgh, 169-172.

[14] Greenberg, S. (1996). Teaching Human Computer Interaction. Interactions, July-August, 62-76. 
https://doi.org/10.1145/234813.234820

[15] Lizano, F. \& Stage, J. (2014). Improvement of Novice Software Developers' Understanding about Usability: The Role of Empathy toward Users as a Case of Emotional Contagion. Proceedings of the $16^{\text {th }}$ International Conference on Human-Computer Interaction, Crete, 207-218. https://doi.org/10.1007/978-3-319-07233-3_20

[16] Rosenbaum, S., Rohn, J. A., \& Humburg, J. A. (2000). A Toolkit for Strategic Usability: Results from Workshops, Panels, and Surveys. Proceedings of the CHI, Hague, 337344. https://doi.org/10.1145/332040.332454

[17] Gulliksen, J., Boivie, I., Persson, J., Hektor, A., \& Herulf, L. (2004). Making a Difference: A Survey of the Usability Profession in Sweden. Proceedings of the $3^{\text {th }}$ Nordic Conference on Human-Computer Interaction, Tampere, 207-215. https://doi.org/10.1145/1028014.1028046

[18] Adam, A. \& Kreps, D. (2009). Disability and Discourses of Web Accessibility. Information, Communication \& Society, 12(7), 1041-1058. https://doi.org/10.1080/13691180802552940

[19] Kavcic, A. (2005). Software Accessibility: Recommendations and Guidelines. Proceedings of the International Conference on Computer as a Tool, Belgrade, 1024-1027. https://doi.org/10.1109/EURCON.2005.1630123

[20] Youngblood, S. A. (2012). Communicating Web Accessibility to the Novice Developer: From User Experience to Application. Journal of Business and Technical Communication, 27(2), 209-232. https://doi.org/10.1177/1050651912458924

[21] Lazar, J., Dudley-Sponaugle, A., \& Greenidge, K. (2004). Improving Web Accessibility: A Study of Webmaster Perceptions. Computers and Human Behavior, 20(2), 269288. https://doi.org/10.1016/j.chb.2003.10.018

[22] Holzinger, A. (2005). Usability Engineering Methods for Software Developers. Communications of the ACM, 48(1), 71-74. https://doi.org/10.1145/1039539.1039541

[23] Lethbridge, T. C. (2000). What Knowledge is Important to a Software Professional? Computer, May, 44-50. https://doi.org/10.1109/2.841783

[24] Liebenberg, J., Huisman, M., \& Mentz, E. (2014). Knowledge and Skills Requirements for Software Developer Students. International Journal of Social, Behavioral, Educational, Economic, Business and Industrial Engineering, 8(8), 2604-2609.

[25] Kuşçu, Ö., Çetiner, H., Gökmen, H. T. (2013). Tarihçeve Akademik Kadro Açısından Türkiye'de Bilgisayar Mühendisliği Eğitimi. Suleyman Demirel University Journal of Natural and Applied Science, 17(1), 38-44.

[26] Öğrenci Seçme ve Yerleştirme Sistemi (OSYM), Yükseköğretim Programlarıve Kontenjanları Kılavuzu (2015). http://dokuman.osym.gov.tr/pdfdokuman/2015/ OSYS/2015-OSYSKONTKILAVUZU01072015.pdf

[27] Türk, A. M. \& Bilge, A. (2015). Bilgisayar Mühendisliği Eğitiminde Teknoloji Eğilimlerinin Takip Edilmesi. Electronic Journal of Occupational Improvement and Research, 3, 119-129.

[28] Babanlı, A. (2006). Bilgisayar Mühendisliği Eğitimi ve Problemleri. Proceedings of the 3. Ulusal Elektrik Elektronik Bilgisayar Mühendislikleri Eğitimi Sempozyumu, İstanbul.

[29] Alaybeyoğlu, A., Morkaya, Ö. (2006). Ülkemizdeki Bilgisayar Mühendisliği Lisans Eğitimiile Yazılım Mühendisliği Lisans Eğitiminin Karşılaştırılması. Proceedings of the 3. Ulusal Elektrik Elektronik Bilgisayar Mühendislikleri Ĕgitimi Sempozyumu, İstanbul.

[30] KSTU. The History of Kyrgyz State Technical University, $\mathrm{http}: / / \mathrm{kstu} . \mathrm{kg} /$ istoriya-kgtu/

[31] NSCKR (2014). Education and Science in the Kyrgyz Republic. Statistical Yearbook, http://stat.kg/media/ publicationarchive/e92fa220-6092-4b80-ab669941553f73e3.pdf
[32] Nielsen, J. (2012). Usability 101: Introduction to Usability. https://www.nngroup.com/articles/usability-101introduction-to-usability/

[33] ISO 9241-210 (2010). Ergonomics of human-system interaction - Part 210: Human-cantered design for interactive systems.

[34] Elliott, M. \& Kling, R. (1997). Organizational Usability of Digital Libraries: Case Study of Legal Research in Civil and Criminal Courts. Journal of the American Society for Information Science, 48(11), 1023-1035. https://doi.org/10.1002/(SICl)10974571(199711)48:11<1023::AID-ASI5>3.0.CO;2-Y

[35] Kujala, S., Roto, V., Väänänen-Vainio-Mattila, K., Karapanos, E., Sinnelä, A. (2011). UX Curve: A Method for Evaluating Long-Term User Experience. Interacting with Computers, 23, 473-483. https://doi.org/10.1016/j.intcom.2011.06.005

[36] McCarthy, J. \& Wright, P. (2004). Technology as Experience. Interactions, 11(5), 42-43. https://doi.org/10.1145/1015530.1015549

[37] W3C WAI (2005). Introduction to web accessibility. http://www.w3.org/WAI/intro/accessibility.php

[38] Oxford Dictionary. https://en.oxforddictionaries.com/ definition/accessibility

[39] ISO 9241-171 (2008). Ergonomics of human-system interaction - Part 171: Guidance on software accessibility

[40] Hoegh, R. T. Usability Problems: Do Software Developers Already Know? Proceedings of the $8^{\text {th }}$ Australia Conference on Computer-Human Interaction. Sydney, 2006, 425-428. https://doi.org/10.1145/1228175.1228264

[41] Bruun, A. \& Stage, J. (2015). New Approaches to Usability Evaluation in Software Development: Barefoot and Crowdsourcing. The Journal of Systems and Software, 105, 40-53. https://doi.org/10.1016/j.jss.2015.03.043

[42] Inal, Y. \& Guner, H. (2016). Understanding Software Developers' Awareness and Knowledge about User Experience and Usability. Pamukkale University Journal of Engineering Sciences, 22(5), 384-389. https://doi.org/10.5505/pajes.2015.83792

[43] Boivie, I., Gulliksen, J., \& Göransson, B. (2006). The Lonesome Cowboy: A Study of the Usability Designer Role in Systems Development. Interacting with Computers, 18, 601-634. https://doi.org/10.1016/j.intcom.2005.10.003

[44] Lopes, R., Isacker, K. V., \& Carriço, L. (2010). Redefining Assumptions: Accessibility and its Stakeholders. Proceedings of the $12^{\text {th }}$ International Conference, ICCHP 2010, Vienna, 561-568. https://doi.org/10.1007/978-3-642-14097-6_90

\section{Contact information}

Yavuz INAL, Postdoctoral Fellow

Department of Information Science and Media Studies,

Faculty of Social Sciences, University of Bergen,

Fosswinckels gate 6,5020, Bergen, Norway

yvzinal@gmail.com

Rita ISMAILOVA, Assistant Professor

Department of Computer Engineering

Faculty of Engineering, Kyrgyz-Turkish Manas University,

Engineering Building, Chingiz Aitmatov Campus, Djal,

720038 Bishkek, Kyrgyz Republic (Kyrgyzstan)

rita.ismailova@manas.edu.kg 